\title{
A model of water quality in a coal mine in the Western Blue Mountains of NSW, Australia
}

\author{
S. Riley ${ }^{1}$, C. McQuade ${ }^{2}$ \& D. Cohen ${ }^{1}$ \\ ${ }^{1}$ Sustainable Engineering and Technology Research Group, \\ University of Western Sydney, Australia \\ ${ }^{2}$ Business Support, Zinifex Port Pirie Smelter, Australia
}

\begin{abstract}
Metal contamination of sediments can be an issue for mine sites discharging water. Water sampling of receiving waters is frequently undertaken, but examination of sediment is less common. This paper reports on a study of the water quality of an underground long-wall mine in the western Blue Mountains Coal district of New South Wales. Clarence Colliery is located at the headwaters of the Wollangambe River, N.S.W, and discharge flows through the world heritage listed area of the Blue Mountains and Wollemi National Park. The impact of the discharge of treated mine water on the Wollangambe River, through analysis of sediment metal concentrations, is quantified and possible sources and causes of acid mine drainage within the mine assessed.
\end{abstract}

Keywords: coal mining, mine water management, water quality.

\section{Introduction}

Water released from the Clarence Colliery site enters the Wollangambe River (Fig 1). The environment could be adversely impacted if the quality of water released from the Colliery is not as good or better than the condition of the surrounding environment. Waters that may be quite safely discharged into the surrounding environment at a particular site may present a high risk of having polluting effects if discharged into another environment. The interaction of discharged waters with the surrounding environment can be difficult to predict and measure.

The concentration of metal ions in the sediment of a river is often much higher than experienced in the water column. This is due to the ongoing 
processes of oxidation and reduction that remove the dissolved metal ions from the water column and bind the metals into the sediment. Metals in the form of suspended material in the water column can also settle out into sediment. Even slight changes in metal concentrations in the water column could cause significant changes in sediment concentrations (Stigliani et al. [1]). Excessive build-up of metal concentrations in sediments can create conditions that impact plant and animal species exposed to the river system. The effects of metals on plant and animal species are complex and specific to individual organisms. They can be acute, where the effects occur after a short period of exposure, or chronic, where the effects are seen after prolonged exposure periods. They are also not purely concentration based and depend on parameters such as water oxygen content, temperature, salinity, metal speciation, and other chemical species present at the time (Förstner and Wittmann [2]).

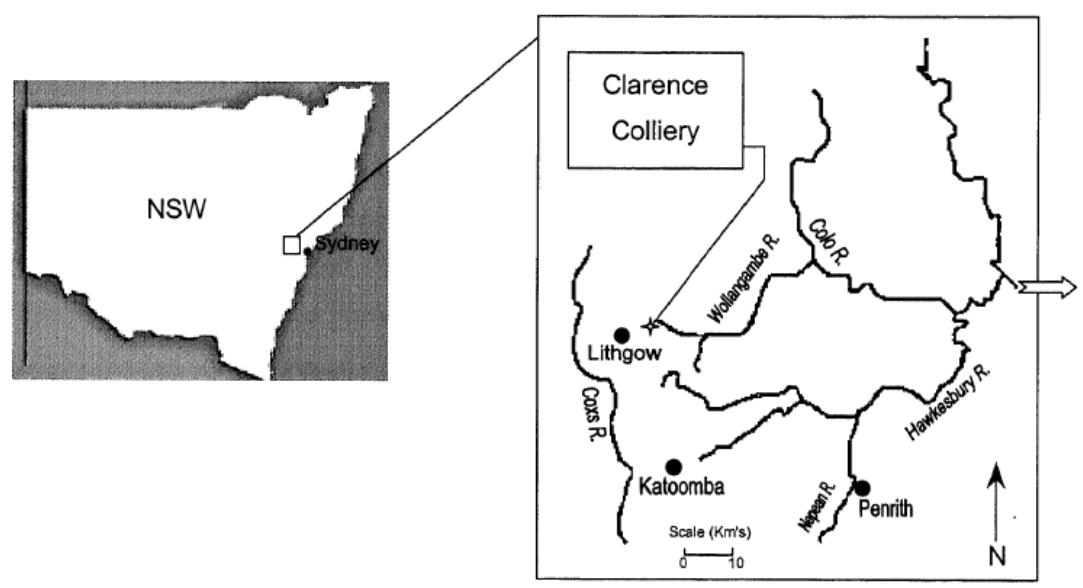

Figure 1: $\quad$ Location of Clarence colliery and surrounding streams.

A sampling program was devised to determine the spatial distribution of selected metals within the sediments of the river. Sampling was conducted at sites along the river course, with sites being located both above and below the colliery's discharge point. A regional picture of metal concentrations along the Wollangambe River was then developed. Conclusions were then drawn about the effects of water releases from the colliery upon fluvial sediment in the Wollangambe. The sampling scheme developed did not include sampling of the sites in the study at different times, for example during summer and winter. It was considered that seasonal variation would have little impact on the results obtained.

Finkelman [3] reports the modes of occurrence of metals in bituminous coals (as found at Clarence Colliery). It should be noted that coals are highly variable in their composition, and this information is intended only as a rough guide to where the metals in question may be coming from in water from the colliery. The following list includes only the metals examined in the Wollangambe River 
regional sediment study. A wide variety of other metals are also present in the water removed from Clarence Colliery, which have sources similar to the metals below.

\section{Cobalt}

- $\quad$ Most likely associated with sulphide minerals (especially pyrite)

- Smaller amounts may also be associated with fine grained accessory sulphide minerals and clays and organic material (although this is more like applicable to low grade coals, such as brown coal)

Iron

- $\quad$ Primary component of pyrite

- Also present in small amounts in organic material Manganese

- Mostly occurs in solid solution with the carbonate minerals siderite $\left(\mathrm{FeCO}_{3}\right)$ and ankerite $\left(\mathrm{CaFe}\left(\mathrm{CO}_{3}\right)_{2}\right)$

- May also be organically associated, but this is primarily attributed to lower grade coal types

- Generally present in higher concentrations than any other trace metal (which excludes iron as it is not classified as a trace metal)

Nickel

- Generally, great uncertainty exists as to the most likely mode of occurrence

- Thought to be substantially bound into organic material in the coal

- Small amounts are also thought to sometimes be associated with pyrite

Zinc

- $\quad$ Thought to mostly occur as sphalerite $(\mathrm{ZnS})$

- Small amounts are also thought to sometimes be associated with pyrite

Groundwater flows into the tunnels and other underground open spaces from the surrounding rock strata. The majority of the water infiltrates through fractures and other strata discontinuities (Poppitt [4], Australian Groundwater Consultants [5]). Water can also percolate through the more porous strata formations, such as sandstone, into the workings of the mine. This water needs to be removed from underground to prevent flooding. Dewatering of the underground workings at Clarence Colliery up to 2002 was of the order of $14 \mathrm{ML}$ of water per day.

\section{Methodology}

The aim of the sampling strategy was to derive, for each site sampled along the river, an estimate of the loading of metal per unit area of riverbed, regardless of what type of sedimentary material was encountered. A clear problem with reporting only metal concentrations (based purely on metal per unit weight of sediment) became evident. Variables such as the density of the sedimentary material, to what depth it extended, and how much of a particular type of sediment existed at the sampling site, would not allow a clear indication of contamination to be gained. For this reason, samples were collected from a set area at nodes of a grid with a mesh spacing of $2 \mathrm{~m}$, to a set depth. The concentration of metal for each sample was derived from the analysis of the 
sediment. This information was then combined with the weight of material collected from the set area at each node. A loading, in terms of mass of metal per unit area (to a set depth of $25 \mathrm{~mm}$ or less), could then be determined. A clear picture of how much metal was present at each site along the river could then be gained, even though sedimentary environments along the river were not similar. Systematic sampling provides unbiased results, providing the position of the starting node is randomly selected.



Figure 2: Location of sampling points along the Wollangambe River.

Based on previous studies, the metals identified above were judged to be the key elements in terms of concentration change across the colliery's water discharge point, being elevated to levels that have the potential to create toxicity problems

Standard methods were employed for the preparation and analysis of the sediment samples. This included US EPA method number $3050 B$ (US EPA [6]) for the digestion of the samples, and Section 3111 of Standard Methods for the Examination of Water and Wastewater (APHA [7]) for the flame atomic absorption spectrometry (AAS) method of analysis. These standard methods represent well characterised and validated procedures. The preparation and analysis methodology is outlined in Cohen [8]. Fractions of sediment examined include sand, biofilms, fine sand and mud. Samples were pooled and sub-site samples also examined. An example of the results is shown for site W1 is illustrated in Figure 3.

Considerable variability in metal content exists in the sediments within the immediate area of the sampling site. The main influence on the sediment metal content at any given location is the variety of sediment types and grain size that may be encountered. The sampling methodology employed in the study had to account for this variation in the metal contents that was shown to exist at each sampling site. An analysis of the variance generated by varying numbers of subsite samples revealed that 15 sub-site samples should be taken from each site 
sampled. This ensured that variance in the resulting data was kept to an acceptable level, while the effort required to process and analyse the samples was minimised.
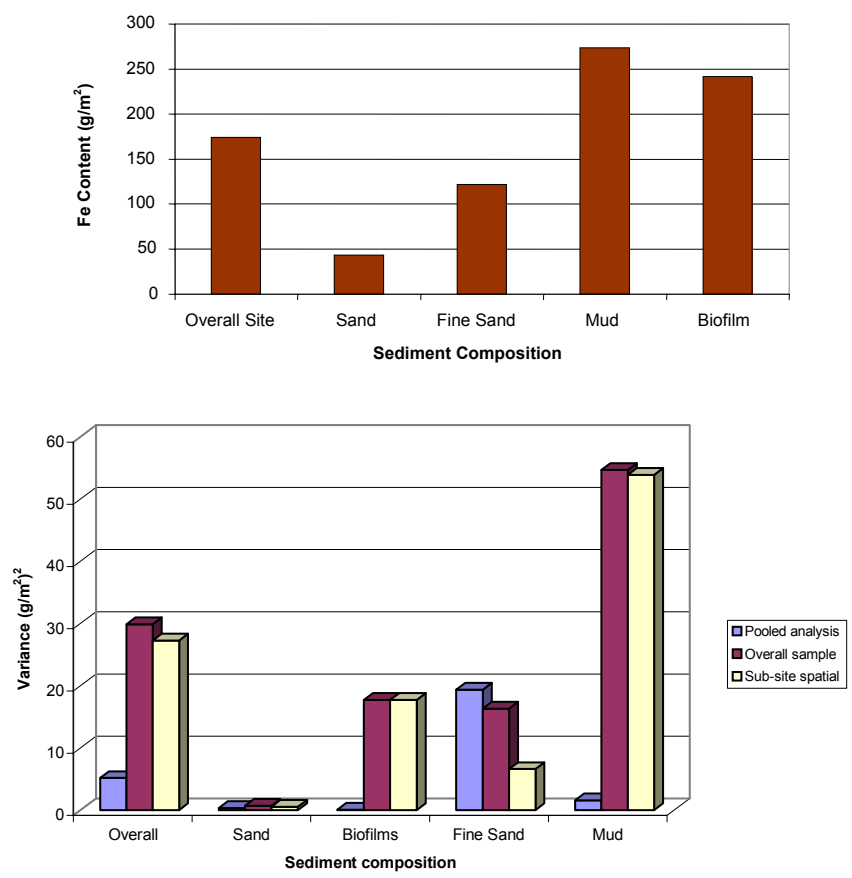

Figure 3: $\quad$ Means and variations of iron at site $\mathrm{W} 1$ for different fractions.

\section{Results}

The distributions indicate the following trends:

- Manganese is more strongly associated with the biofilm collected from the river than any other metal. This indicates that they are actively taken up and held by the biofilm.

- Iron is associated with biofilm, but not as strongly as manganese. The mud taken from the sample area was found to have high iron concentrations. This indicates that iron is being taken up and held by biofilms, and is associated with the fine-grained materials taken from the site. The iron could be attached to the surface of the fine-grained materials in the mud, or its floc like precipitate could be a component of the mud itself.

- Cobalt was found to have elevated concentrations within the biofilm material, but was also associated with mud and fine-grained sand.

- Nickel and zinc were both found not to have elevated concentrations within the biofilm taken from the sampling site. This could indicate that living organisms within the biofilm are not actively taking up these metals. 
- Nickel was associated with the sand and fine grained sand material more than any other metal.

Overall, no general conclusion can be drawn about any particular type of sedimentary material having greatly increased metal loading over other sedimentary types. It is often generalised that fine-grained sedimentary material holds the most significant loading of metal. This was not found, and it can be clearly seen that each metal is in fact different in terms of association with sedimentary material. This could have significant impact in terms of certain metals being distributed differently along the course of the Wollangambe River, as differing sedimentary materials transported differently within river systems.

At each site sampled, the sub-site samples were averaged to give an indication of the metal loading for the site. The average metal loading, in terms of mass of metal per unit area of riverbed, for each site sampled in the Wollangambe River Regional Sediment Study is shown in Table 1.

Table 1: $\quad$ Mean Metal contents for each of the sites sampled all figures are in $\mathrm{g} / \mathrm{m}^{2}$ of sediment sampled \pm one standard deviation.

\begin{tabular}{|c|c|c|c|c|c|c|}
\hline Metal & Site W1 & Site W2 & Site W3 & Site W4 & Site W5 & Site W6 \\
\hline Co & ${ }_{0.09}^{0.14}{ }^{ \pm}$ & ${ }_{0.09}^{0.07} \pm$ & $\begin{array}{l}6.97 \\
3.20\end{array}$ & ${ }_{3.69^{ \pm}}{ }^{ \pm}$ & ${ }_{0.83}^{1.21} \pm$ & ${ }_{1.66}^{0.86}$ \\
\hline $\mathrm{Fe}$ & $\begin{array}{r}174 \\
172\end{array}$ & $\begin{array}{ll}49 & \pm \\
29 & \end{array}$ & $157 \pm 57$ & $64 \pm 38$ & $59 \pm 58$ & $35 \pm 18$ \\
\hline $\mathrm{Mn}$ & $\begin{array}{l}4.5 \pm \\
6.3\end{array}$ & ${ }_{0.2^{0.38}}^{ \pm}$ & $\begin{array}{l}51.0 \pm \\
34.8\end{array}$ & $\begin{array}{l}76.7 \\
38.4\end{array}$ & $\begin{array}{l}8.9 \pm \\
8.7\end{array}$ & $\begin{array}{r}4.9 \pm \\
10.8\end{array}$ \\
\hline $\mathrm{Ni}$ & $\begin{array}{l}0.12^{ \pm} \\
0.07^{ \pm}\end{array}$ & ${ }_{0.05^{ \pm}}^{0.03}$ & ${ }_{8.83}{ }^{ \pm}$ & ${ }_{4.20}^{7.36}{ }^{ \pm}$ & ${ }_{0.75^{ \pm}}^{0.87}$ & ${ }_{0.59}^{0.45}{ }^{ \pm}$ \\
\hline $\mathrm{Zn}$ & ${ }_{0.19^{ \pm}}^{0.25}$ & $\begin{array}{l}0.14^{ \pm} \\
0.07^{ \pm}\end{array}$ & ${ }_{14.33^{ \pm}}^{24.08}$ & ${ }_{9.15}{ }^{ \pm}$ & $\begin{array}{l}1.59 \\
1.37^{ \pm}\end{array}$ & $\begin{array}{l}0.511^{ \pm} \\
0.50^{ \pm}\end{array}$ \\
\hline
\end{tabular}

Mud tends to have high concentrations of all metals at each site, but this conclusion is somewhat limited by the absence of mud samples at sites W5 and W6. Manganese seems to be the exception to this trend, with by far the highest concentrations of the metal being found in biofilms. Biofilms also generally contain high concentrations of all metals, although the biofilm data was extremely limited due to the fact that samples of biofilm were only found at sites W1 and W6.

Sand and coarse sand samples all experienced peak metal loading directly below the discharge point for all metals examined (excepting sand samples, which had peak manganese loading $3 \mathrm{~km}$ downstream of the release point). Fine sand experienced peak loading of cobalt, manganese and nickel $3 \mathrm{~km}$ downstream of the release point and peak loading of iron and zinc directly below the release point. Mud samples experienced peak loading of all metals directly below the discharge point. This may be due to the settling of fine particles with high metal 
concentrations (such as metal oxides), settling out at this point. No conclusions could be drawn about the biofilm samples, due to discontinuity of the data for this sediment type.

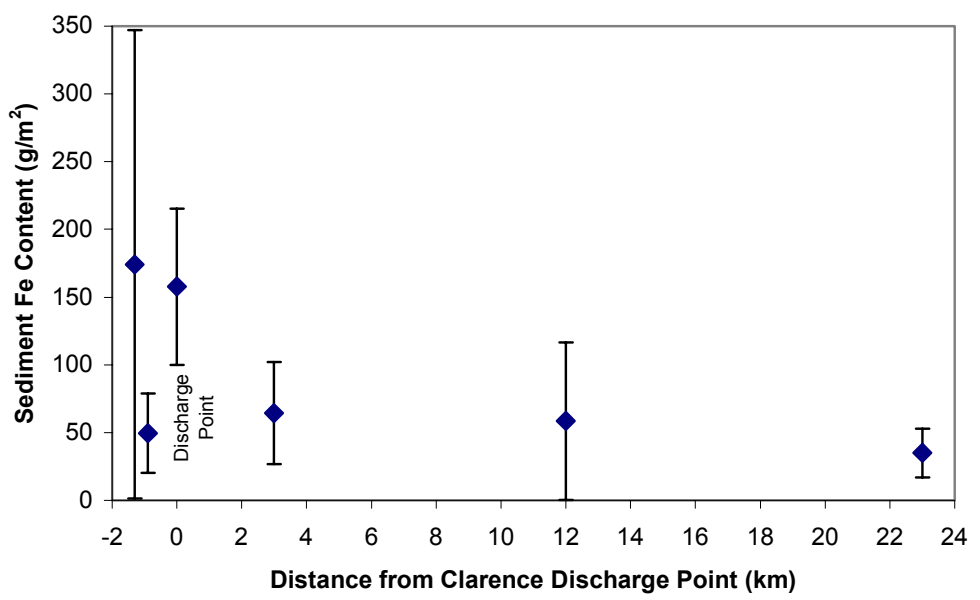

Figure 4: Distribution of iron concentration in sediments along the Wollangambe River.

In general, the profiles for each of the sediment types follow the general trend observed in the overall metal content profiles. Low metal contents are encountered at the two sites above the release point. There is then a sharp rise at the first site below the release point, followed by a gradual decrease in metal content downstream of the discharge point. Metal contents fall to relatively low levels at the sites furthest from the discharge point. This trend seems to apply to all of the metals examined in the study.

The biofilm samples collected from site W6 show particularly high manganese contents, indicting that manganese may be concentrating in the biofilm layers for some distance below the Clarence Colliery discharge point.

The study aim was to quantify the effects of Clarence Colliery's discharge into the Wollangambe River. The aim was achieved through the collection and analysis of sediment samples from sites along the river. The conclusions drawn from the study are outlined in the following section. This includes a discussion of the significance of the values encountered, and implications for best practice management of mine water at the colliery.

\section{Discussion}

Muds and biofilms show the highest average metal contents of all of the types of sedimentary materials collected. This is due to the higher surface area that attracts and hold metal ions in muds, and the ability of biofilms to adsorb and bind soluble metal ions. Manganese contents were particularly high in biofilms encountered in the study. 
There is generally a sharp increase in metal content directly below the Clarence Colliery release point (site W3), compared to the background levels experienced at the two sites above the discharge point (W1 and W2). Nickel and zinc have the highest metal concentrations directly below the Clarence Colliery discharge point. Cobalt and manganese have the highest metal concentrations three kilometres downstream of the Clarence Colliery discharge point.

The metal contents of the sediments at sites W5 $(12 \mathrm{~km}$ downstream of the colliery) and W6 (23 km downstream) drop off significantly for all of the metals included in the study. The last site examined in the study exhibits metal contents comparable to those encountered at the sites sampled above the Clarence Colliery discharge point (which were used as background levels). Cobalt tends to exhibit the greatest increase over background levels at the last site examined in the study.

Metal loading may be attenuated by the dilution of flows from Clarence Colliery by tributary streams and groundwater inflows along the course of the river. This would cause a decrease in sediment metal concentrations as the river progresses along its course, due to lowered metal concentrations in the water column.

The increased metal content in the sediment directly below the Clarence Colliery discharge point is most likely attributed to one or both of the following factors. The first is that metals released in the water discharged from Clarence Colliery are concentrating in the sediment. The second factor is that the increased $\mathrm{pH}$ of water being discharged from the site is causing soluble metal ions to precipitate out of both the water being discharged and the water from upstream in the Wollangambe River. The $\mathrm{pH}$ at site $\mathrm{W} 1$ is 6.53 , the $\mathrm{pH}$ at $\mathrm{W} 2$ is 5.2 and the $\mathrm{pH}$ at site $\mathrm{W} 3$ (just downstream of the discharge point) is 7.2.

\section{Conclusion and climate-change induced management response}

A viable option for managing discharge, proposed by the owners of the mine'is related to the fact that Clarence Colliery lies only several hundred meters from the catchment divide for Farmers Creek and Wollangambe River. Farmers Creek flows to the west of the Colliery, through the city of Lithgow and into the Coxs River. The Wollangambe River flows to the east of the Clarence Colliery. Coxs River is utilised for storage supply dams for nearby power stations owned and operated by Delta Electricity. These dams have caused severe depletion of flow within the Coxs River, creating major environmental problems. The discharge of $14 \mathrm{ML}$ of treated mine water per day into this catchment would alleviate some of the stresses on the Coxs River.

The Farmers Creek catchment is much less pristine, flowing through urbanised areas, and already receiving treated sewage effluent. The Farmers Creek catchment is classed as a Class "C" watercourse under the Clean Waters Regulations 1972, and is subject to much less stringent discharge conditions than the Wollangambe River which is a Class "P" watercourse. The mine could save 
money by neutralising the waters only, as this level of treatment would probably result in waters suited for discharge into a Class " $\mathrm{C}$ " watercourse.

Water from the mine would need to be pumped over the catchment divide, where gravity would take over and carry the water into the river. The idea of transferring treated mine water to the Farmers Creek catchment was raised in an article published in the Lithgow Mercury Newspaper on August 17, 1999. The current operators of Clarence Colliery put forward the proposal as one management option currently being considered for released mine water.

A scheme such as this, that has the potential to provide added benefit to the general community, must be seen as the perfect solution to the problem at hand. The prolonged drought of 2002 to 2007, largely attributed to greenhouse related climate change, saw this option taken up.

\section{Acknowledgements}

The work was funded through a grant from Clarence Colliery Pty Ltd and subsequent owners. We thank NPWS for access to the remote sections of the Wollangambe River, mine staff for assistance with monitoring and access to data, and staff at UWS who assisted with chemical analysis, in particular Professor Sam Adeloju.

\section{References}

[1] Stigliani WM, Doelman P, Salomons W, Schulin R, Smidt GRB and van der Zee SEATM, 1991. Chemical Time Bombs: Predicting the Unpredictable, Environment 33; 4-30

[2] Förstner U and Wittmann GTW, 1979. Metal Pollution in the Aquatic Environment, Springer-Verlag, Berlin Heidelberg p 64-66

[3] Finkelman RB 1995. Modes of Occurrence of Environmentally Sensitive Trace Elements in Coal. In Swaine DJ and Goodarzi F (eds), Environmental Aspects of Trace Elements in Coal, Kluwer Academic Publishers, Dordrecht, The Netherlands

[4] Poppitt IL, 1984. Wrench Faulting and Associated Structures, Clarence Colliery, Western Coalfield, NSW, Master of Applied Science Thesis (unpublished)

[5] Australian Groundwater Consultants, 1983. Clarence Colliery Hydrogeological Study, Report 879 (unpublished)

[6] US Environmental Protection Agency, 1986. Test Methods for Evaluating Solid Waste: Physical/Chemical Methods, SW-846, USEPA Office of Solid Waste and Emergency Response, Washington, DC, USA

[7] APHA, 1995. Standard Methods for the Examination of Water and Wastewater, 19th Edition, American Public Health Association, American Water Works Association, and the Water Environment Federation.

[8] Cohen, D. 2002. Title, Best practice mine water management at a coal mining operation in the Blue Mountains. MEng(Hons) thesis, University of Western Sydney. Unpublished 